\title{
Activity, Judgment, and Recognition in Nicole Oresme's Philosophy of Perception
}

\section{Silva, José Filipe}

Springer-Verlag

2020

Silva , J F 2020 , Activity, Judgment, and Recognition in Nicole Oresme's Philosophy of

Perception . in D Bennett \& J Toivanen (eds), Philosophical Problems in Sense Perception.

: Testing the Limits of Aristotelianism . Studies in the History of Philosophy of Mind,

Springer-Verlag , pp. 239-253 . https://doi.org/10.1007/978-3-030-56946-4_14

http://hdl.handle.net/10138/338877

https://doi.org/10.1007/978-3-030-56946-4_14

acceptedVersion

Downloaded from Helda, University of Helsinki institutional repository.

This is an electronic reprint of the original article.

This reprint may differ from the original in pagination and typographic detail.

Please cite the original version. 


\title{
Activity, Judgment, and Recognition in Nicole Oresme's Philosophy of Perception
}

\author{
José Filipe Silva
}

[Abstract: This paper provides evidence for the interpretation offered by Grellard, according to which Oresme defends an active model of perception. It follows the roots of this view to Augustine and approaches the topic from the perspective of the possibility of error in perceptual process.]

\section{Introduction}

Knowledge of external objects was a central topic to late medieval thinkers. It is fair to say that their general approach was informed by two epistemological theses: first, under normal environmental conditions, we perceive the world in an accurate way. Second, episodes of perception require the existence of certain psychological conditions that explain how we come to perceive certain objects in the world. ${ }^{1}$ One of such conditions is attention, which we can tentatively define here as a kind of spotlight brought to bear upon some, rather than other, objects or aspects of objects. ${ }^{2}$ The first thesis concerns the way information about external things is made available to the perceiving subject in a way that is conducive of cognition, so that failures in this mode of availability lead to perceptual errors. The second thesis, on the other hand, concerns the way the information made available to the cognitive subject gains cognitive significance by means of its own internal cognitive mechanisms and processes. As such, failing to meet these conditions does not entail perceptual error, but simply failure to perceive what is present to one's perceptual field.

There is a long philosophical tradition concerning the development of these two theses, taken together or in isolation, that only recently merited sufficient scholarly attention. In a very interesting article in this volume, Christophe Grellard paints in broad brushstrokes the way the medieval philosopher Nicole Oresme (ca. 1320-1382) addresses these two issues: perceptual error and the role of attention in perceptual experience. ${ }^{3}$ His

\footnotetext{
José Filipe Silva (jose.pereiradasilva@helsinki.fi)

Associate Professor in Medieval Philosophy

Faculty of Arts

University of Helsinki

${ }^{1}$ It is best to remain neutral about what is perceived, whether the object in its totality or some aspect(s) of it. This is because of the different levels of description one appeals to, as well as what the mediatory devices called species actually represent - and it is impossible to consider this without focusing on the different philosophical traditions.

${ }^{2}$ On the different kinds of attention in use in medieval theories of perception, see Silva 2017; Toivanen 2013.

${ }^{3}$ There is a third aspect, which is the role of habit in perception and perceptual error. For reasons of space, I cannot discuss this third aspect here. Suffice it to say, I disagree with Grellard in taking Oresme's later developments of the roles of habit and memory in perception as a departure from perspectivist optics, because both these aspects are presupposed in the highest kind of perceptual judgment in Alhacen. In order
} 
overall argument is that perceptual error has great significance for our understanding of medieval theories of perception and that attention or the activity of the soul in perception can be described in terms of 'constructivist psychology' ${ }^{4}$ My aim in this paper is twofold: first, to provide complementary evidence for the existence in Oresme of an active model of perception; second, to show that influences on his model go beyond Avicenna and the perspectivist tradition in geometrical optics, which is the focus of Grellard's analysis. I take it that the notion of attention is that found in medieval Augustinian philosophy of perception. ${ }^{5}$ The reason this is important is that understanding the role of attention in perceptual experience requires that one spells out what kind of attention we are talking about and perhaps more importantly, what motivates its use, i.e. why is attention needed for perception?

\section{$2 \quad$ Erring}

Medieval philosophical thinking about error is determined by two main theses: the first one is that error takes place in acts of composition/affirmation (or division/negation), rather than in simple cognitive acts of apprehension/grasping. That is true of both acts of the senses and acts of the intellect. In fact, the default view is that external senses almost never fail to apprehend their proper objects and the intellect is almost never wrong in its act of grasping a quiddity or essence of a material thing (that is its proper object). ${ }^{6}$ But the similarities between perceptual and intellectual error end here. In the case of the senses, failure to fail is due to the limited range of properties that constitute the proper objects of the particular senses, for instance color as the per se sensible for the sense modality of sight. Either the triggering stimulus is present to actualize the power's capacity for seeing or it is not: so, whenever there is a colored thing present to my field of vision, I cannot, under normal environmental conditions, fail to see that object. Things get more complicated the more complex these sense objects become, like the common sensibles (seize, shape, motion, etc.), and the accidental sensibles (those things in which the per se sensibles exist, like Socrates in which the whiteness I see exists). I may identify the colored thing as something other than what it is (a cat, say, instead of a dog), but failure to identify the thing which is colored is not a failure in a sense modality, but a malfunction of the internal processing capacities that medieval thinkers called internal senses - common sense, imagination, phantasy, memory, estimative power, etc.

The intellect, on the other hand, is characterized by the capacity to identify the essential properties of a thing once presented with the multiplicity of sensory imagery of that thing or that kind of thing in the form of phantasms. That capacity is a primitive feature of the theory, meaning that it is so made as to be able to grasp these essences, despite what seems to be a poverty of sensory stimulus, because it is an immaterial entity directly created by God. But, as the topic of this paper is perceptual error, we can avoid this issue altogether.

to recognize something as being of a certain kind and even as the individual it is, one needs to compare incoming sensory data with stored data (a form of memory access) and do so on the basis of salient features (a form of habit), so that the process is swift. On this, see Hatfield 1993; Silva 2017; Sabra 1978; and Smith 2015.

${ }^{4}$ For an overview of the problems for perception that arise from failing to meet these conditions, see Silva \& Toivanen (2019).

${ }^{5}$ The topic of activity of perception and the psychological phenomenon of attention in medieval philosophy has recently received ample scholarly attention: see e.g. Gannon 1965; Perler 1994; Pasnau 1997; Leijenhorst 2001; Silva \& Toivanen 2010; Silva 2012; Silva 2014a-b; Toivanen 2015; Toivanen 2018.

${ }^{6}$ On the senses, see Aristotle De anima III.3, 428b18; Metaphysics III.5, 1010b18. 
The second thesis that most, if not all, medieval thinkers subscribed to with respect to perceptual error is that error is possible in the transmission of information from the object to the cognitive subject takes place under sub-optimal conditions. Information from and about the external thing takes the form of 'species', here signifying appearances or similitudes of objects or sensible properties of objects. ${ }^{7}$ This is not the place to elaborate on the nature of this species; it suffices for my purposes here, however, to say that by the mid-thirteenth century (and thus by Oresme's time), species were the standard way of explaining how sensory information was made available to a perceiver. This guaranteed the required distance between object and sense organ argued for by Aristotle. ${ }^{8}$ According to Oresme, the species of color, for instance, 'are multiplied in the medium by a certain spiritual power or influence', ${ }^{9}$ and this multiplication takes the form of 'spherical radiation about the object', just like fire warms equally all men standing in a circle around it. ${ }^{10}$ The idea, simply put, is that species radiate in straight lines from each point of the surface of the object in all directions. From an ontological point of view, these species are corporeal entities with spiritual being, meaning that they exist in corporeal media without imparting that media with the qualitative feature they represent. ${ }^{11}$ Failure in the environmental conditions (medium, sense organs, distance) ${ }^{12}$ of transmission of species leads to a failure in the exercise of the cognitive operations and thus to cognitive error. For instance, as Oresme notes,

if the eye is in a rarer medium and the object in a denser medium, the object appears nearer to the vision than if seen through a uniform medium. (...) [on the other hand,] when the eye is in a denser medium and the object in a rarer medium, the object appears farther from sight than if the medium were uniform. ${ }^{13}$

The same happens to all sorts of cases, like that of the stick half immersed in water, which appears to be broken or bent, or of a coin (denarius) fully immersed in water, which appears to be larger than it is. The only way a system designed for epistemic success can err is when 'a breakdown in the system' has taken place, ${ }^{14}$ and, in this Aristotelian framework, changes in the conditions of the medium constitute precisely that. In the presence of standard conditions, we cannot fail to perceive how things are because the contents of those experiences depend on the appropriated grasp of our sense modalities and the objective existence in things of those perceived properties. ${ }^{15}$ Aristotelian

\footnotetext{
7 'species is a certain quality similar to an object which represents it naturally', Questiones de anima III.10, $101-2$.

${ }^{8}$ One of the clearest presentations of Oresme's view on species can be found in his Questiones super quatuor libros metereorum, which is edited by S.C. McCluskey, Jr in Nicole Oresme on Light, Color, and the Rainbow: An Edition and Translation, with Introduction and Critical Notes, of Part of Book Three of his 'Questiones super quatuor libros meteororum'. PhD Dissertation, University of WisconsinMadison, 1974.

${ }^{9}$ Oresme, Questiones super quatuor libros metereorum 12.57-9, 130.

10 'omne agens multiplicat virtutem suam prope se orbiculariter', Oresme, Questiones super quatuor libros metereorum 13.108-9, 170. The example and application to the generation of the species is Oresme's.

${ }^{11}$ Oresme, Questiones de anima II.18, 168-71. In what follows, I use both Marshall's and Patar's editions, referred to respectively as Questiones de anima and De anima.

${ }^{12}$ Questiones de anima II.10, 293.

${ }^{13}$ Oresme, Questiones super quatuor libros metereorum 12, 153.

${ }^{14}$ Evans 1998: 122.

${ }^{15}$ A good example in Oresme is with the colors of the rainbow, which are seen as being in the sky but are not there. The cause of the error about a proper sensible is then in the less than adequate conditions of the medium (the air and water, in the form of raindrops). See McCluskey 1974: 72, and Oresme, Questiones super quatuor libros metereorum 20.212-16.
} 
metaphysics trumps Theaetetus' skepticism on the value of perception, so much so that the problem of error - even perceptual error - remains marginal for Aristotle. ${ }^{16}$

That is true for the simple acts of cognition, but the major source of error is the act of composition and thus judgement. The kind of judgment I have in mind as the common medieval usage is that whereby one judges that something has a certain property, i.e. of the form $\mathrm{x}$ is $\mathrm{y}$ (or $\mathrm{x}$ is not $\mathrm{y}$ ). It is important to note that this conception of judgment is in no way dependent on language and thus has no propositional form, despite the fact that we need language to describe it. To some extent, all medieval epistemologists would accept that perceptual judgment is part of a perceptual experience: the common sense judges that $\mathrm{x}$ is $\mathrm{y}$ whenever it brings together the sensible properties acquired by the individual external senses. If one were to take the production of perceptual judgments as the sign of activity of the soul in perception, then all medieval epistemologists would accept the view that the soul is active in perception. If that were the case, however, it would be unclear of what philosophical interest the question of activity of perception would have. One way is to argue that the soul is active because the reception of sensory information from the external world is necessary, but not sufficient, for perception, including perceptual discrimination. Instead, the soul must attend to the reception of this sensory information for it to gain cognitive significance. Oresme follows this path, in particular when discussing the problem of the agent sense in his Questiones de anima.

Attention becomes the key feature to explain how the soul is active in perception. There is, however, a minor concern with this account, enough to perhaps curb our enthusiasm: Is attention a primitive feature that is self-caused or is attention a psychological mechanism that explains a reaction to incoming stimuli? If the latter, it seems that the soul is not active, but simply reactive: when I kick a plastic ball, the form of my foot is pressed in upon its structure - and thus one could say that it actively takes on that shape - and bounces forward. Such activities are actualizations of potential states that are caused by the external thing rather than originating in the ball itself. Again, this is not philosophically very interesting. The way out is to argue that the soul is active in perception not because (a) it produces a judgment about material objects and their sensible (visible, tactile, etc.) properties, but because (b) it is the fact that the soul is active that such perceptual judgments can be produced and indeed are so produced. In medieval terms, this could be expressed as follows: according to (a) an act of the external senses is the cause of the act of the internal sense, whereas according to (b) the act of the internal sense is what makes the act of the external sense cognitively significant. Nicole Oresme argues for (b) and he does so by, while operating in a largely Aristotelian framework, giving up two central Aristotelian epistemological theses:

(T1) perceptual acts are caused by external objects (by means of incoming sensory information)

(T2) the content of a perceptual act is determined solely by the incoming sensory information

Before continuing, let me point out, firstly, that nothing in my argument depends on the clause 'by means of incoming sensory information' in T1. I included it there in order to make the relation with $\mathrm{T} 2$ more immediate. To explain how this works without that clause would require too much space. Secondly, there may be some disagreement about whether these two theses (or one of them) represents the view of any medieval Aristotelian, ${ }^{16}$ On this, see Keeler 1934: 8-9, 22-40. On a similar attitude in medieval thinkers, see Silva \& Toivanen
(2019). 
without qualification. I accept this objection, but I would still argue that it expresses something essential to the Aristotelian view on perception, however qualified.

\section{$3 \quad$ Attending}

In the previous section, I suggested a number of alternative proposals concerning the ways in which the activity of the soul can be found in perception. Some of these are not active in a strong sense, i.e. as characterizing cognitive acts that are not caused by their subject. According to that way of understanding activity, acts of judgment are active in a way that is neither original nor significant. Instead, I proposed that we take cognitive operations of the soul as active in a strong sense if these are acts caused by the soul and their contents are not fully determined by the incoming sensory information. That is the view we find in Nicole Oresme.

As Grellard notes in his contribution, attention gains particular traction in Oresme because he understands perception as a cooperation between external and internal senses, which is to say that only when the information is received in the internal sense can we say that the external thing is actually perceived. This is so because perceptual experience necessarily includes perceptual judgment, which only the internal sense can access? (more on this below). The real motivation for this idea is found in the thesis that cognitive acts cannot be caused in the same way as other natural acts. Oresme quotes Aristotle's De anima II.2 and II.4 as evidence for his claim that the soul is the cause of all vital operations, among which perception is to be included. ${ }^{17} \mathrm{He}$ further connects this principle with the fact that perception is an immanent action; that is to say, the act of the perceiver starts and ends in the perceiver. ${ }^{18}$ As a result, Oresme goes on to conclude:

the sense is the agent with respect to sensation. This is proved by the fact that, as said before, it does not suffice that the species is in the organ, but sensation requires that the sense turns [to the object]. And such turning is to act; and thus, in sensing, reasons because, as it has been said, to reason is to act. ${ }^{19}$

The central thesis in this model is a clear distinction between the passive aspect of sensation, which consists in the reception of the incoming sensible species in the organ and the soul's active act of turning to the object: together they constitute perception. Proof of this is that when the species is found in the sense organ, but the sense power is distracted with another thing, there is no perception of the thing causing the species. Further proof of this activity, Oresme argues, is that the sense gets tired (fatigatur) from extended and intense activity, which would not be the case were they simply passive. ${ }^{20}$ (Oresme notes that this fatigue is not due to the operation proper to the material power, but the concomitant activity, like the moving of the corporeal spirits. $)^{21}$

\footnotetext{
17 'dicit quod anima est causa agens respectu omnium operacionum vitalium', II.9, Questiones de anima 272.

18 'non dicitur actio immanens nisi quia est in agente', Questiones de anima II.9, 273.

19 'sensus est agens respectu sensationis. Probatur quia, ut dictum est, non sufficit quod species sit in organo, sed cum hoc requiritur quod sensus advertat quando est sensacio. Et taliter advertere est agere; et eciam senciendo discurrit, ut dictum est, et discurrere est agere', Questiones de anima II.9, 282.

${ }^{20}$ Questiones de anima II.9, 277. Also De anima II.8, 179, where he calls the sense 'virtus fatigabilis'.

${ }^{21}$ De anima II.8, 180.
} 
Oresme's approach gives weight to sense and object as efficient contributing causes ${ }^{22}$ but with an emphasis on the productive nature of the soul:

I say that sense receives the species from the sensible [thing] and by means of it produces [an act of] sensation in itself-in the same way as a heavy thing receives, from its generator, its weight, by means of which it moves itself. ${ }^{23}$

What sense then does is to 'act sensation', which we could express in a less awkward way as 'bringing about a perceptual experience' from the species made or caused by the object. $^{24}$ But in fact, it means something stronger. In DA II.9, 279 Oresme claims that the sensible form - which represents internally the external thing - is not distinct from the perceptual act. What this means, then, is that the distinction is more radical than assumed: the sense organ is acted by the external thing impressing the sensible species in it and the sense power is acted upon by itself in so far as it produces a corresponding internal sensible form. That is why Oresme notes that there are two ways in which the sense is acted upon (pati): as the ultimate subject receiving something from an agent, like it receives the species from the object; and, on account of which that reception is made, which is for the sense to be acted upon by itself in sensing by producing and receiving the form. ${ }^{25}$ This self-action is possible because the soul is not the full cause, but co-cause, the other being the reception of the species in the organ. The senses cannot be completely active in perception: first, were it the case, one would be able to sense at will, without a corresponding object in the extra-mental world; second, sensation is a change of state, meaning that one moves from the non-exercise of the operation (e.g. seeing) to its exercise; third, sensation cannot entail extra-mission because we do not act upon things in the world, like stars, simply by turning our gaze to them. The species, which is in the outer part of the sense organ, is produced by the object and not the power. ${ }^{26}$

The sense is the principal cause and the reception of the species in the organ is the instrumental cause. If the sense — or the sensitive soul—were not active, the species could never be found in the internal sense, the operation of which (as will be seen below) is necessary for perception, because of the way species propagate: in straight lines. Whereas that mode of propagation is appropriated to the medium, it is not proper to the twisted pathway (per lineam tortuosam) connecting the sense organs and the brain, where the internal sense is located. ${ }^{27}$ Only the activity of the sensitive soul producing a representation of the thing impressed upon its sense organ, which is dependent on but not caused by the reception of the species, makes this transmission and thus perception possible.

Oresme's view is that the object moves the sense organ (sensibile movet sensum), qua instrumental cause, and the soul causes the act of sensation (sensus agit sensationem), qua primary cause. ${ }^{28}$ The sense acts by making 'the species caused by the sensible thing to be sensation'. ${ }^{29}$ Oresme offers two reasons why the soul/the sense must be active: first,

22 'Igitur sensacio principalius dependet ab anima quam ab obiecto efficiente, quamvis utrumque concurrat', Questiones de anima II.9, 283.

23 'dico quod sensus recipit a sensibili speciem et, mediante ipsa, in semetipso agit sensacionem-sicud grave a generante recipit gravitatem mediante qua postead movet se ipsum', Questiones de anima II.9, 283.

24 'Et tunc sensus agit sensacionem vel facit speciem factam vel causatam a sensibili esse sensacionem', De anima II.9, 284.

${ }^{25}$ Questiones de anima II.9, 279.

${ }^{26}$ De anima II.9, 187.

${ }^{27}$ Questiones de anima II.9, 281-82.

${ }^{28}$ Questiones de anima II.9, 283-84.

29 'Et tunc sensus agit sensationem vel facit speciem factam vel causatam a sensibili esse sensationem', De anima II.9, 189. 
the soul must be active because that which is active is superior and nobler (nobilius) than that which is passive; ${ }^{30}$ second, cognitive (including perceptual) acts are vital acts and immanent operations. ${ }^{31}$ The nobility of a substance is expressed in its properties and operations. This means that the soul must be the efficient cause (causa agens) of all vital operations, including the cognitive ones, rather than being causally subjected to the action of a material external thing. Both these theses are stock medieval Augustinian philosophy of perception, as I have argued elsewhere. ${ }^{32}$

\section{Processing}

In the previous section, the focus was on the cause of perceptual acts, rather than on the nature of the process itself. Processing of sensory information does not of itself entail activity in the strong sense, because that would be to confuse performing an operation and being the cause of that operation: the windmill grinds the grain, but that action is caused by the wind, not by the mill itself. Likewise, sense powers such as the internal sense faculties - e.g. the common sense-operate on the basis of received sensory information. In order for an internal representation of an external thing to come to exist, the species must be transmitted and received in the organ in a way that conforms to basic geometrical rules:

for such representation it is necessary that pyramids are continually erected upon the eye, since for vision the arrangement of species or rays in the eye must be such that just as that which is seen is disposed outside, in like manner it is represented inside. ${ }^{33}$

Following the model of geometrical optics of the perspectivists, especially Alhacen in his De aspectibus, Oresme argues that visual perception is defined by a visual pyramid with the vertex in the center of the eye and the base terminating at the extremes of the surface of the visible object. ${ }^{34}$ This guarantees that everything seen is seen within that pyramid in a way that bears a one to one representation of the external thing. In explaining this, Oresme also follows Roger Bacon's version of the intromission theory of vision, his doctrine of the multiplication of species. According to this, objects in the world issue species of their sensible properties. These properties can be perceived either per se, or by accident.

Largely inspired by Alhacen, Oresme argues for a distinction between those things that we perceive by external sense alone, its proper objects, like colour and light for sight, and those that require some form of reasoning (discursus), which are all other properties of objects, traditionally called the 'common sensibles'. These features of things, like place, rest, motion, etc. are, according to Oresme, accidental sensibles in that they are not the object of one sense modality only, they are not perceived without reasoning, and the

\footnotetext{
${ }^{30}$ De anima II.8, 181.

${ }^{31}$ De anima II.8, 183.

${ }^{32}$ Silva 2014b; Silva 2017a; Silva (forthcoming)a; Silva (forthcoming)b; Silva (forthcoming)c. Both these aspects can be found in authors such as Henry of Ghent, Peter John Olivi, Durandus of St. Pourçain, Roger Marston, etc.

${ }^{33}$ Oresme, Questiones super quatuor libros metereorum 13, 177.

34 'omnis res, quantum ad longitudinem et latitudinem de qua nunc loquimur, videtur sub pyramide cuius basis est res visa et vertex est in oculo secundum aliquem angulum’, De anima II.13, 217.
} 
object does not issue forth species of them. ${ }^{35}$ These properties are perceived accidentally because they are not perceived by means of their proper species. ${ }^{36}$ Instead, they are perceived together with the perception of the proper sensibles: when perceiving a white thing, we perceive its whiteness together with, rather than in isolation from, its shape, size, location, distance, etc. ${ }^{37}$

Oresme is particularly aware that material objects may appear in ways that do not correspond to the way they are in the world. One of the reasons for this, that we have briefly considered already, is due to problems in the environmental conditions, as when there is a red glass between us and a wall, leading us to perceive the wall as red. It is true that we perceive red, the error is that we judge the red to be where it is not. ${ }^{38}$ Another cause is the productive nature of the internal senses, namely the faculty of imagination, directly or by means of the action of bodily humours. Oresme illustrates this with the case of one spinning around and when stopping the objects around us seem to continue to spin despite one remaining still. Something similar happens when one sees something as the result of being in an altered state, due to excess of love or madness. Other cases are the result of faulty processing of information, like when one confuses the size of objects in the visual field by not including distance in our perceptual judgment. That is the case when different objects, as a wolf and a forest, are seen under an equal angle and thus are incorrectly judged to be of the same size. ${ }^{39}$

What this reveal is that simple reception of sensible species in the sense organs cannot be enough for sensation and furthermore that perception does not take place in the external but rather in the internal sense. In fact,

the external sense does not cognize, but the internal [does so] by means of the external. ${ }^{40}$

Those two acts are truly inseparable (inseparabilia) because there is no operation of one without the act of the other. ${ }^{41}$ Oresme makes this claim even more compelling by noting that what is present to the external senses is a necessary, but not sufficient condition in the process of producing a complex judgement that is either true or false. ${ }^{42}$

Oresme emphasizes the complex nature of sensitive cognition, meaning that it always has form of a judgment such as $\mathrm{x}$ is $\mathrm{y}$. But there are different levels of judgment. Oresme remarks that perceptual judgments can have as their predicates, a general form, as 'something is coloured', or a specific form, as 'something is blue', or an even more specific form, as 'something is of such a hue of green'. ${ }^{43}$ With the exception of the first kind, i.e. perception of a general form that Oresme also calls 'confused' (confuso)

\footnotetext{
${ }^{35}$ Oresme, Questiones de anima II.11, 308-10. Oresme is aware and is explicit that this conception of sensibile per accidens is not that of Aristotle, but that which is found in Perspectivist treatises. See De anima II.12, 208.

36 'debet dici sensibles per accidens quod non potest cognosci nisi per discursum quia tale non immediate cognoscitur per suam speciem', Questiones de anima II.11, 310.

37 'dico quod non oportet quod figura agat in sensum sed $<$ quod $>$ color agit speciem figuratam vel album agit speciem albam representative et figuratam magnam', Questiones de anima II.14, 349. According to Alhacen, there are twenty such sensibles, which include the common sensibles from Aristotle.

${ }^{38}$ De anima II.10, 195.

${ }^{39}$ Oresme, Questiones super quatuor libros metereorum 19.309-14, 254.

40 'sensus exterior non cognoscit sed interior mediante exteriori', Questiones de anima II.10, 288.

${ }^{41}$ De anima II.10, 192.

42 'visum est quoniam nulla sensacio est sine iudicio complexo vero aut falso', Questiones de anima II.10, 295.

${ }^{43}$ Questiones de anima II.10, 289. It is interesting to note that Oresme is very precise when describing the subject of that property as something (aliquid), rather than a thing of a given kind, like human being or animal.
} 
universal, the two determinate kinds of perceptual content - 'this is white' and 'this is of that shade of white' - require the activity of the reasoning internal sense. ${ }^{44}$ About the first kind, which is mostly free from error, Oresme simply says that it is done without reasoning and by the external sense. This is slightly confusing because he has just denied that there can be perception by the external sense only. What he probably means is that this is the only kind of perception whereby its content is fully determined by the received information. For all other cases, Oresme thinks that perceptual judgment is produced on the basis of information immediately accessible to-i.e. received in - the sense organ and in addition information that is not immediately available in this way. This requires supplementary work by the discriminative power (virtus distinctiva), which proceeds by association (per collacionem) and comparison (per comparacionem) of different sensible features ${ }^{45}$ both present to the senses and previously stored. This comparison allows the judgment not only that something is $\mathrm{x}$ but also that it is different from $\mathrm{y} .{ }^{46}$

I propose to illustrate this with one example. I am looking at the ceiling of the Leonine room in the Vatican Library, where I am writing these words. There is an array of colours and geometrical figures, as well as a panel with three angels holding a book. I can focus on any of the figures at will, paying close attention to small details, like the drape of one of the angels, or the background colour, in this case blue, etc. The question is whether what I consciously see is determined only by what there is in the ceiling present to my visual field. One answer is to say yes, because it is the fact that certain colours, shapes, etc. are present to me in the way they are - with the environmental conditions being standard ones, in terms of illumination, my eyes are healthy, the distance to the ceiling is appropriate - that I cannot fail to perceive the way I do. Oresme makes this point clear when he notes that

vision judges colours to be there; therefore, they are truly there. The antecedent is apparent; and the consequence is valid, for otherwise vision would be deceived, which contradicts Aristotle [where he] says in the second of De anima that vision is not deceived, at least [not] in judging what is colour, although it would be deceived in judging what is white or black. ${ }^{47}$

The sense modality of sight does not fail to perceive under the optimal conditions, that is, what its proper objects, colour and light (lumen in the air and lux at the source) are, although it may fail to perceive accurately - i.e. to identify - the thing to which that sensible feature belongs: what thing is that white (thing). ${ }^{48}$ On the other hand, Oresme makes it clear that even in the case that one is deceived about the origin of the sound, it is still true that a sound is heard. ${ }^{49}$

But that is the minimal account of visual perception, that which has light and colour as its proper objects. In addition, when we perceive things like this ceiling that I am currently looking at, what I see must be determined by what I am already acquainted with, so that I can report that 'I see an angel with blue wings and blond curly hair, partially

\footnotetext{
44 'Et istud iudicium non fit solo sensu exteriore, sed cum hoc concurrit sensus interior discursivus', $D e$ anima II.12, 207.

${ }^{45}$ Questiones de anima II.10, 290.

${ }^{46}$ De anima II.12, 207.

${ }^{47}$ Oresme, Questiones super quatuor libros metereorum 20, 261.

${ }^{48}$ Oresme argues for two important theses about the proper objects of sight, light and colour: first, that colour is not simply the effect of the action of light upon an opaque body, but the result of 'the mutual interaction of primary qualities'; second, that both light and colour are seen. See Oresme, Questiones super quatuor libros metereorum 20, 262-70.

${ }^{49}$ 'Nec valet si obicitur de tinitu aurium, quia in rei veritate est ibi quidam sonus, licet non [sit] talis qualis apparet aut tantus', Questiones de anima II.10, 292.
} 
covered with a yellow drape'. I can do it only because I know, from previous experiences, what an angel is, what wings are, what the colour blue looks like, etc. So, it does make sense to argue, like Alhacen does and then Oresme, that the received sensory information is just part of the content of the visual experience I am having. Perception conceived of as limited to what is made immediately present to us at a given time ignores other perceptual capacities that we do possess, namely the capacity to recognize objects. Recognition is nothing but the capacity to identify a given object or property as something of which we have a prior experience and thus to have access to that knowledge about the object in question. Recognition is a central feature of perspectivist optics and there are many reasons why such an ability is an essential part of normal human perceptual processes. One of them is the swiftness of perception that is made faster, if we can apply what we know - and remember - to the incoming sensory information, without having to go again and again (upon any instance of encountering that object) through the process of apprehending its relevant properties.

Grellard's suggestion is precisely that, according to Oresme, our visual perceptions include more than meets the eye (pun intended). What we see is not limited to the objects as they affect us, but memory and habit have a role to play in how we perceive the world. I certainly agree with him. One example of this extra-received information is the perception of distance, as distance between objects in the visual field is not one of the sensible properties that are available to us, at least from the immediate perspective of visual perception. ${ }^{50}$ Another is the perception of motion, on which Grellard focuses his attention. Oresme explicitly considers the perspectivist model an improvement with respect to the Aristotelian one on the issue, when he remarks:

It seems hence that motion is perceived by sight, not by itself, but mediately and almost by accident, just like [stated] in the beginning of the third [book] of Perspective. And if it is said that Aristotle calls it a common sensible and per se sensible, $<$ it must be said $>$ that he spoke in a general and coarse-grained way. ${ }^{51}$

Oresme takes perception in general to be more accurate if that which is perceived is already known. For instance, in order to know whether something has moved, we need to know that it was first at rest and from this judge that it is no longer at rest but in motion. This cannot be the function of sight, which can, on its own, see a or b, but not their motion. That is why Oresme, when explaining the perception of motion, talks of the sensitive soul in terms of a receptive power that retains different past moments of the continuous motion of a thing and the power of discriminating between these moments and the present place of that thing, resulting in a judgment that the thing has moved. ${ }^{52}$ For that "judging by

${ }^{50}$ On the perception of distance in perspectivist optics, see Silva 2017: $56-8$.

51 'Patet ergo quod motus percipitur per visum, non tamen per se, sed mediante et quasi per accidens, sicut $<$ patet $>$ in principio tertii Perspective. Et si dicatur quod Aristoteles dicit quod est sensibile commune et sensibile per se, <dicendum $>$ quod loquebatur in generali et grosse', Nicole Oresme, Physics in Nicolaus Oresmes Kommentar zur Physik des Aristoteles, ed. S. Kirschner. Stuttgart: Steiner, 1997, III.1, 296. There is also a new edition by S Caroti et al., Nicole Oresme, Questiones super Physicam (Books I-VII). Brill, 2013.

${ }^{52}$ De anima II.15, 234. Grellard (footnote 25) attributes a certain confusion to Oresme, but it seems to me that this apparent confusion can be explained away by considering perception - in a very Augustinian fashion-from the point of the soul, rather than from the point of view of powers. Perceptual powers are functions of one subject, which is the sensitive soul. The soul receives and retains by one power and discriminates and judges by another. 
means of sight' (iudicatur mediante visu), one needs the distinctive and judging power (virtus distinctiva et iudicativa). ${ }^{53}$

Furthermore, in the perception of quantity, one needs to possess and make use of a certain standard or yardstick to measure that quantity, which is akin to saying that I measure this wall as being four metres long-metre being my measure of choice. In that sense, one is more prone to err precisely because of the complex nature of this judgment, composing/dividing or comparing, as it is the case of the illusion of perceiving that trees in the shore are moving, while on board of a moving boat. We do not perceive motion if we look at those things that move with us; instead, to perceive motion we need to compare visible things and realize that they occupy different places at different times-but the time as the distance must be moderate. ${ }^{54}$ In some cases, the perception is of what moves fast and thus requires just the discriminative power together with short-term memory, which is the work of phantasia. In other cases, still, memory properly has to play a role, like the case of the motion of the sun: as the movement takes so long that the species disappear from the common sense, memory (reminiscentia) must retain those species and reason must judge, on their basis, that the sun has moved. ${ }^{55}$ Finally, there are some longterm motions that are not properly called perception but knowledge of motion, like the motion of the heavens, which is performed by the intellect. ${ }^{56}$ This last kind of judgment is properly human, i.e. non potest percipi a brutis.

\section{Conclusion}

From the examples just presented in the previous Section and the analysis provided there and in Grellard's paper, it seems safe to conclude that for Oresme our perceptual experiences (of the specific kind, at least) are not, content wise, fully determined by the information we received in the sense organs from external objects. That being the case, the causal process between object and perceiver is not sufficient on its own to explain how and what - of the things present to our perceptual field - we actually perceive. In order to explain it, we need to bring on the way we attend to these objects, as we have examined above, but also the way we process sensory information. On this latter aspect, it is worthwhile to point out again two significant features in Oresme's account, which he explicitly associates with Alhacen: the first is that the more general something is, the more immediate its perception is - the levels of specification of the content of perceptual acts are progressive and increasingly time consuming; this is so, because specification (or determination) requires more reasoning than the confused universal. The second feature is that these modes of apprehension and specification by 'reasoning' are common to all beings capable of perception. ${ }^{57}$ What this ultimately means is that the discriminative power, which performs these higher order perceptual processes, is not of a rational kind, as it is found all over the animal kind. Together, these two aspects show that Oresme's

\footnotetext{
53 'Et talia precise non cognoscuntur a sensu exteriori, sed cum adiuntorio virtute distinctive, quam Aristoteles vocat sensum communem, et etiam patet in Perspectiva', Nicole Oresme, Physics III.1, 294.

${ }^{54}$ De anima II.15, 232-33.

${ }^{55}$ Nicole Oresme, Physics III.1, 302-3. On the different degrees of certitude attainable by these modes of cognition, see J. Celeyrette, 'Apparences et imaginations chez Nicole Oresme: Question III.1 sur la Physique et question sur l'apparence d'une chose', Revue d'histoire des sciences, tome 60:1 (2007), 83-100.

${ }^{56}$ De anima II.15, 235-36.

57 'et hoc est universale in omnibus animalibus habentibus sensus', Questiones de anima II.10, 291.
} 
model brings together elements from the Augustinian and the perspectivist theories of perception and that his is a strong active-perception theory. ${ }^{58}$

\section{Bibliography}

\section{Primary Sources}

Nicole Oresme, Physics in Nicolaus Oresmes Kommentar zur Physik des Aristoteles, ed. S. Kirschner. Stuttgart: Steiner, 1997; new edition by S Caroti et al., Nicole Oresme, Questiones super Physicam (Books I-VII). Brill, 2013.

— The 'Questiones super de celo' of Nicole Oresme. Edited, with English translation by Claudia Kren. Ph.D. Dissertation, University of Wisconsin, 1965.

- The 'Questiones de spera' of Nicole Oresme. Latin text with English translation, commentary, and variants, edited by Garrett Droppers. Ph.D. Dissertation, University of Wisconsin, 1966.

— Nicole Oresme and the Marvels of Nature: A Critical Edition of His 'Quodlibeta' with English Translation and Commentary, edited by Bert Hansen. Ph.D. Dissertation, Princeton University, 1974.

— Nicole Oresme on Light, Color, and the Rainbow: An Edition and Translation, with Introduction and Critical Notes, of Part of Book Three of his 'Questiones super quatuor libros meteororum', edited by Stephen C. McCluskey, Jr. Ph.D. Dissertation, University of Wisconsin- Madison, 1974.

— Nicolai Oresme Expositio et Quaestiones in Aristotelis De Anima, edited by Benoît Patar. Louvain-Paris 1995.

- Questiones super Libros Aristotelis de Anima, edited by Peter Marshall. PhD dissertation, Cornell University, 1980.

\section{Secondary Sources}

Celeyrette, J. 'Apparences et imaginations chez Nicole Oresme: Question III.1 sur la Physique et question sur l'apparence d'une chose', Revue d'histoire des sciences, tome 60:1 (2007), 83-100.

Evans, G.R. Getting It Wrong. The Medieval Epistemology of Error. Brill 1998

Hatfield, G. Perception and Cognition. Essays in the Philosophy of Psychology. Oxford, Clarendon Press, 2009.

Keeler, L.W., S.J., The Problem of Error from Plato to Kant. A Historical and Critical Study. Rome: Pontificiae Universitatis Gregorianae, 1934

Leijenhorst, C. 'ATTENTION PLEASE! Theories of Selective Attention in Late Aristotelian and Early Modern Philosophy', in P.J.J.M. Bakker (ed.) 205-30.

Mahoney, E.P. 'Agostino Nifo's De Sensu Agente', Archiv für Geschichte der Philosophie 53 (1971), 119-142.

Perler, D. Théories de l'intentionnalité au moyen âge. Vrin, 2003

\footnotetext{
${ }^{58}$ The research for this paper has been funded by the European Research Council under the Starting grant agreement n. 637747 for the project Rationality in Perception: Transformations of Mind and Cognition $1250-1550$.
} 
Sabra, A.I. (1978) "Sensation and Inference in Alhacen's Theory of Visual Perception," in P.K. Machamer, R.G. Turnbull (eds.), Studies in Perception: Interrelations in the History of Philosophy and Science. Columbus, Ohio State University Press 1978, pp. $160-185$

Silva, J.F. 'Medieval Theories of Active Perception: an overview,' in J.F. Silva and M. Yrjönsuuri (eds.), Active Perception in the History of Philosophy. Dordrecht: Springer 2014, pp. 117-146.

'Perceptual Judgment in Late Medieval Perspectivist Psychology,' Filosoficky Casopis. Special Issue on Perception in Scholastics and Their Interlocutors 2 (2017), pp. 29-60.

— and J. Toivanen, 'Perceptual Errors in Late Medieval Philosophy', in B. Glenney and J.F. Silva (eds.), The Senses and the History of Philosophy. Routledge, 2019.

Smith, A.M. From Sight to Light: The Passage from Ancient to Modern Optics. Chicago \& London: University of Chicago Press 2015.

Toivanen, J. Perception and the Internal Senses: Peter of John Olivi on the Cognitive Functions of the Sensitive Soul, Leiden: Brill 2013. 